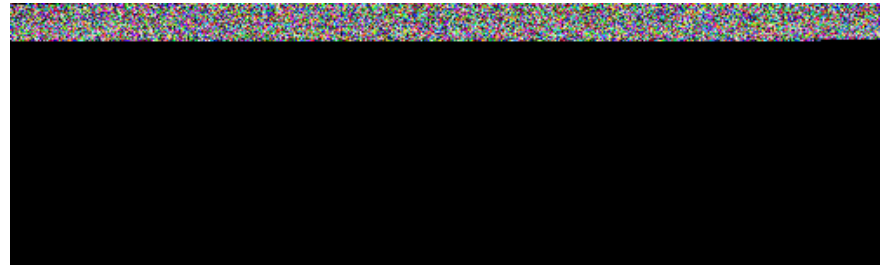

This information is current as of April 26, 2023.

\title{
Imaging Features and Progression of Hyperostosis Cranialis Interna
}

J.J. Waterval, T.M. van Dongen, R.J. Stokroos, B.-J. De Bondt, M.N. Chenault and J.J. Manni

AJNR Am J Neuroradiol 2012, 33 (3) 453-461

doi: https://doi.org/10.3174/ajnr.A2830

http://www.ajnr.org/content/33/3/453 


\section{ORIGINAL RESEARCH}

\section{J.J. Waterval}

T.M. van Dongen

R.J. Stokroos

B.-J. De Bondt

M.N. Chenault

J.J. Manni

\section{Imaging Features and Progression of Hyperostosis Cranialis Interna}

BACKGROUND AND PURPOSE: $\mathrm{HCl}$ is a unique autosomal-dominant sclerosing bone dysplasia affecting the skull base and the calvaria, characterized by cranial nerve deficits due to stenosis of neuroforamina, whereby the mandible is affected to a lesser extent. The aim of this study is to describe the specific radiologic characteristics and course of the disorder.

MATERIALS AND METHODS: CT scans of affected individuals within 1 family were analyzed and compared with scans of their unaffected family members and with an age- and sex-matched control group. Linear measurements were performed of the inner table, the medulla, and the outer table of different skull locations, and attenuation (density) measurements of the same regions were recorded. Neuroforamina widths were recorded as well.

RESULTS: There was significant thickening of the skull in the frontal, parietal, temporal, and occipital regions, which was mainly due to thickening of the inner table of the skull. The attenuation of the deposited hyperostotic bone was lower than normal cortical bone.

CoNCLUSIONS: $\mathrm{HCl}$ is the only genetic bone dysplasia known that is confined to the craniofacial area. The hyperostotic bone is less attenuated than normal cortical bone. The observed radiologic abnormalities explain the possible impairment of the olfactory, optic, trigeminal, facial, and vestibulocochlear nerves.

ABBREVIATIONS: ANCOVA = analysis of covariance; $\mathrm{HCl}=$ hyperostosis cranialis interna; $\mathrm{HU}=$ Hounsfield units; IAC = internal auditory canal

H CI is a hereditary bone disorder characterized by progressive skull-base osteosclerosis and endosteal hyperostosis of the calvaria (Fig 1). Clinical features and the course of the disorder are described in 1 kindred (Fig 2) in the Netherlands. ${ }^{1,2}$ Patients become symptomatic in their late first, second, or third decade due to cranial nerve entrapment. Facial palsy, sensorineural hearing loss, vestibular symptoms, olfactory impairment, optic impairment, and trigeminal neuralgia are the observed symptoms.

Although the emphasis in research of bone dysplasias is shifting toward detection of the genetic and molecular underlying defects, ${ }^{3}$ knowledge of the radiologic features are crucial to diagnose the disorder and to assess progression. The international classification of bone dysplasias is still based on radiologic hallmarks. ${ }^{4} \mathrm{HCI}$ is the only sclerosing bone dysplasia known that is limited to the craniofacial area.

The aim of this study is to describe the initiation of the abnormalities in young patients, to describe the evolution of these abnormalities throughout life, and to quantify differences between HCI patients and control subjects to facilitate early diagnosis. Moreover, better counseling can be provided if the course of the disorder can be more precisely predicted.

Received May 24, 2011; accepted after revision July 5.

From the Departments of Otorhinolaryngology-Head \& Neck Surgery (J.J.W., T.M.v.D., R.J.S., J.J.M.), Radiology (B.-J.D., M.N.C.), Faculty of Health, Medicine and Life Sciences, School of Mental Health and Neuroscience (M.N.C.), and Methodology and Statistics (M.N.C.), Maastricht University, Maastricht, The Netherlands.

Please address correspondence to J.J. Waterval, MD, Department of Otorhinolaryngology and Head \& Neck Surgery, Maastricht University Medical Center, P.0. 5800, 6202AZ Maastricht, The Netherlands; e-mail: J.Waterval@gmail.com

http://dx.doi.org/10.3174/ajnr.A2830

\section{Materials and Methods}

\section{Subjects}

Twenty-two family members-affected group 1 and unaffected group 2- underwent a high-resolution CT scan. Twenty-one control subjects were selected retrospectively, matching for sex and age: group 3 matching group 1, and group 4 matching group 2 . The CT scans were selected from the hospital data base; scans performed with appropriate settings ( $\leq 1-\mathrm{mm}$ section thickness) and without bone abnormalities were considered suitable. The local medical ethics committee approved the protocol (09-4-050.4/pl). All HCI family members gave written informed consent.

\section{CT Imaging and Analysis}

CT scans were performed using helical scanners with 1-mm section thickness in the axial plane; 1-mm reconstructions were made in the coronal and sagittal planes. The local PACS was used for analysis. A protocol for standard measuring was used as follows. Thickness of the frontal, parietal, and occipital regions of the skull were measured in the median line, and 10 and $20 \mathrm{~mm}$ to the right. This was done at various heights, resulting in 10-15 measurements per region under magnification to avoid measuring errors. Thickness of the inner table and outer table of the skull were measured at the same locations. In addition, skull thicknesses were measured at the coronal and lambdoid sutures in the axial plane. Thickness of the inner table of the frontal skull base was measured (sagittal plane, level of the orbital apex), as well as the middle fossa inner table (coronal plane, level of optic chiasm), clivus, and dorsal foramen magnum (sagittal plane, midline).

The diameters of a selection of cranial nerve foramina were measured: the porus and fundus of the internal auditory auditory canal, the optic canal (coronal plane), and the Vidian nerve canal (axial plane) (Fig 3).

Bone attenuation was determined in $\mathrm{HU}$ in different ROIs. 


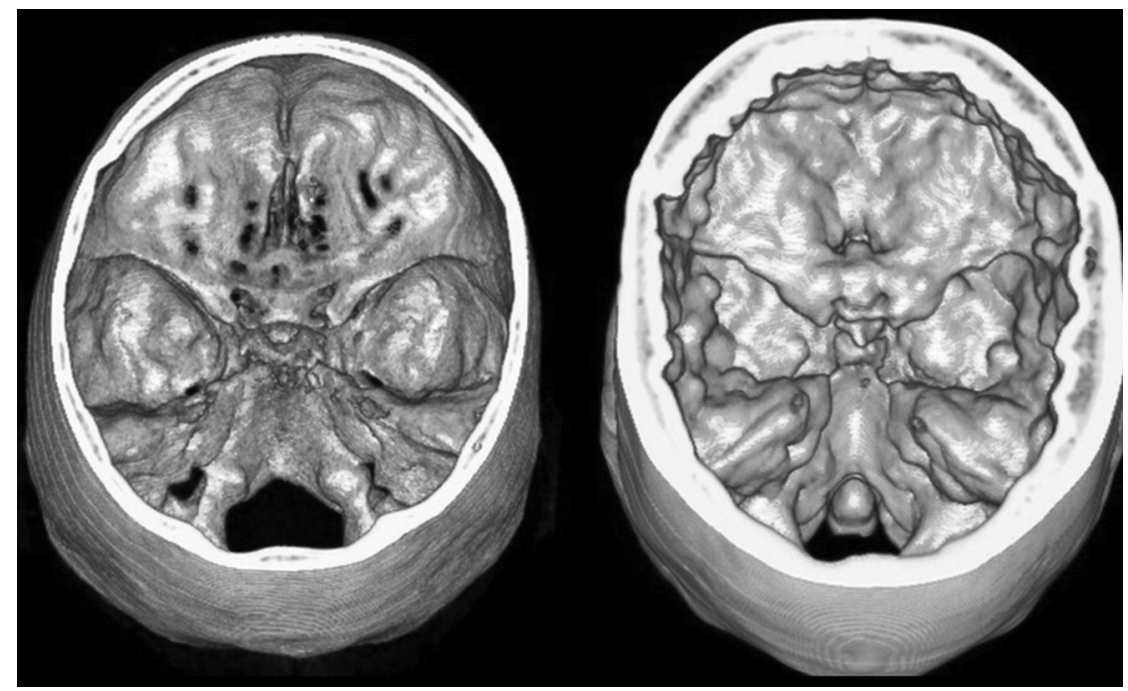

Fig 1. 3D reconstruction of a normal skull base and one of a patient with $\mathrm{HCl}$. The left image is an unaffected individual in whom all neuroforamina can be identified. The right image is an affected individual with thickened calvaria and a bulgy skull base; neuroforamina are hardly visible.

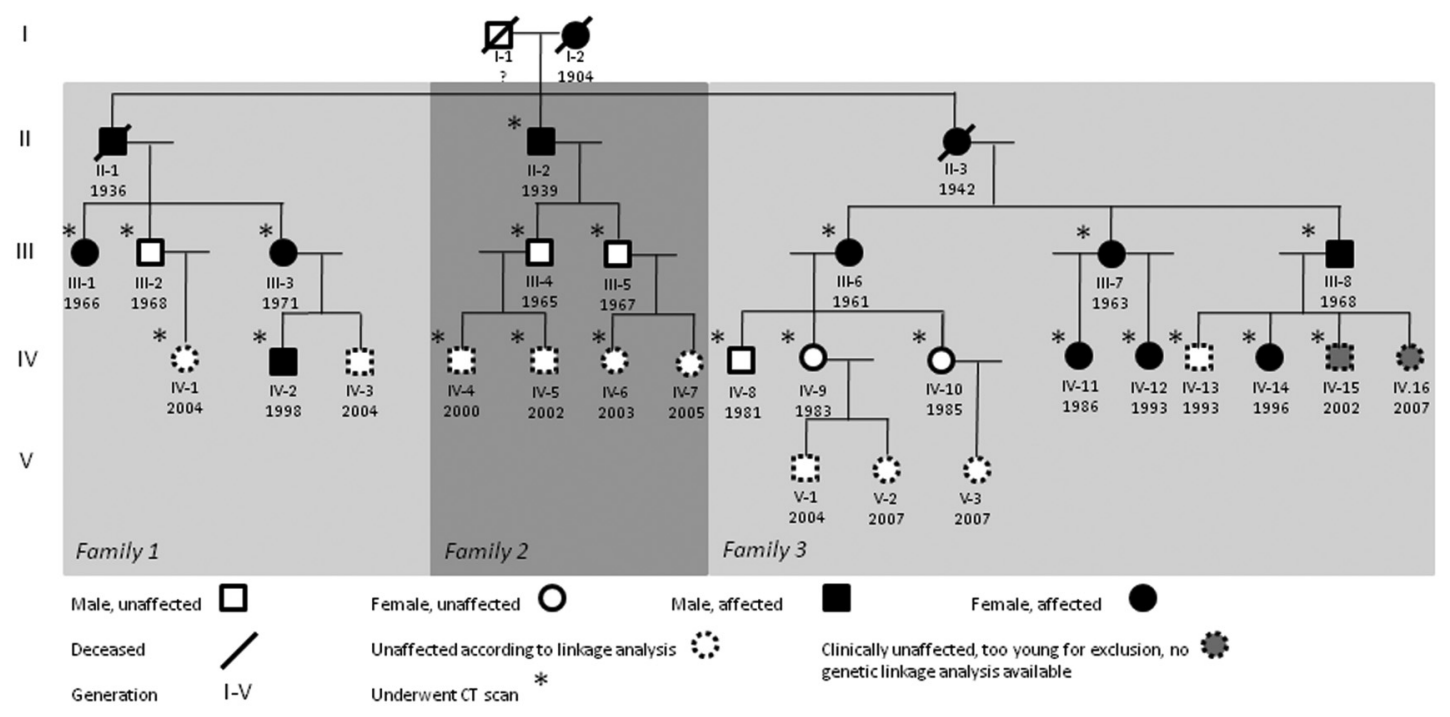

Fig 2. Pedigree of the affected kindred. An asterisk is placed if the individual had undergone a CT scan.

Screening measurements were performed in ROIs in all bone layers: frontal and occipital bone (axial plane, halfway between skull base and vertex, left, right, and median), parietal bone (coronal plane, bilaterally, superior to the mastoid, and halfway skull base to vertex), greater wing of the sphenoid, and apex of the petrous bone (axial plane, bilaterally). To rule out the influence of regional heterogeneous bone attenuation, specific regions were measured (if identifiable) with freehand ROIs (Fig 3C): inner table, outer table, and diploe of both the frontal bone and parietal bones; diploe and inner table of the greater sphenoid wing, (medulla of) clivus, (medulla of) lateral orbit, and sphenotemporal and tympanosquamosal suture; and, if present, exostoses of the mandible.

\section{Statistical Analysis}

The study group was divided into groups 1 and 2, based on diagnosis. Group means of metric measurements (thicknesses and widths) and attenuation measurements were calculated. The KolmogorovSmirnov test was applied to test whether variables with continuous metric values had a normal distribution. Groups 1 and 3, and groups
2 and 4, were compared applying Kruskal-Wallis and Mann-Whitney rank tests when the data could not be considered as normally distributed, and otherwise with paired $t$ tests. To account for physiologic differences in the size of male and female skulls, the same analyses were performed with the ratio inner table:total thickness for the same locations. In addition, the same analyses were repeated after removing the individuals under age 18 to rule out the effect of obvious skull (base) thickening not yet being present in young affected individuals.

The influence of age was assessed with the Pearson correlation or Spearman rank coefficient correlation test, depending on whether normality could be assumed. Univariate ANCOVA was performed to assess the influence of sex. Due to the small group sizes, adjustment for sex and age did not occur simultaneously.

Bone attenuation was analyzed in the same manner as the linear measurements. Groups 1 and 3 were compared using paired $t$ tests. The inner table of the greater sphenoid wing and the 3 components of the parietal bone could not be separately measured, in most cases, in group 3, and therefore we chose to consider the frontal bone (inner table) values of group 3 as reference values. 

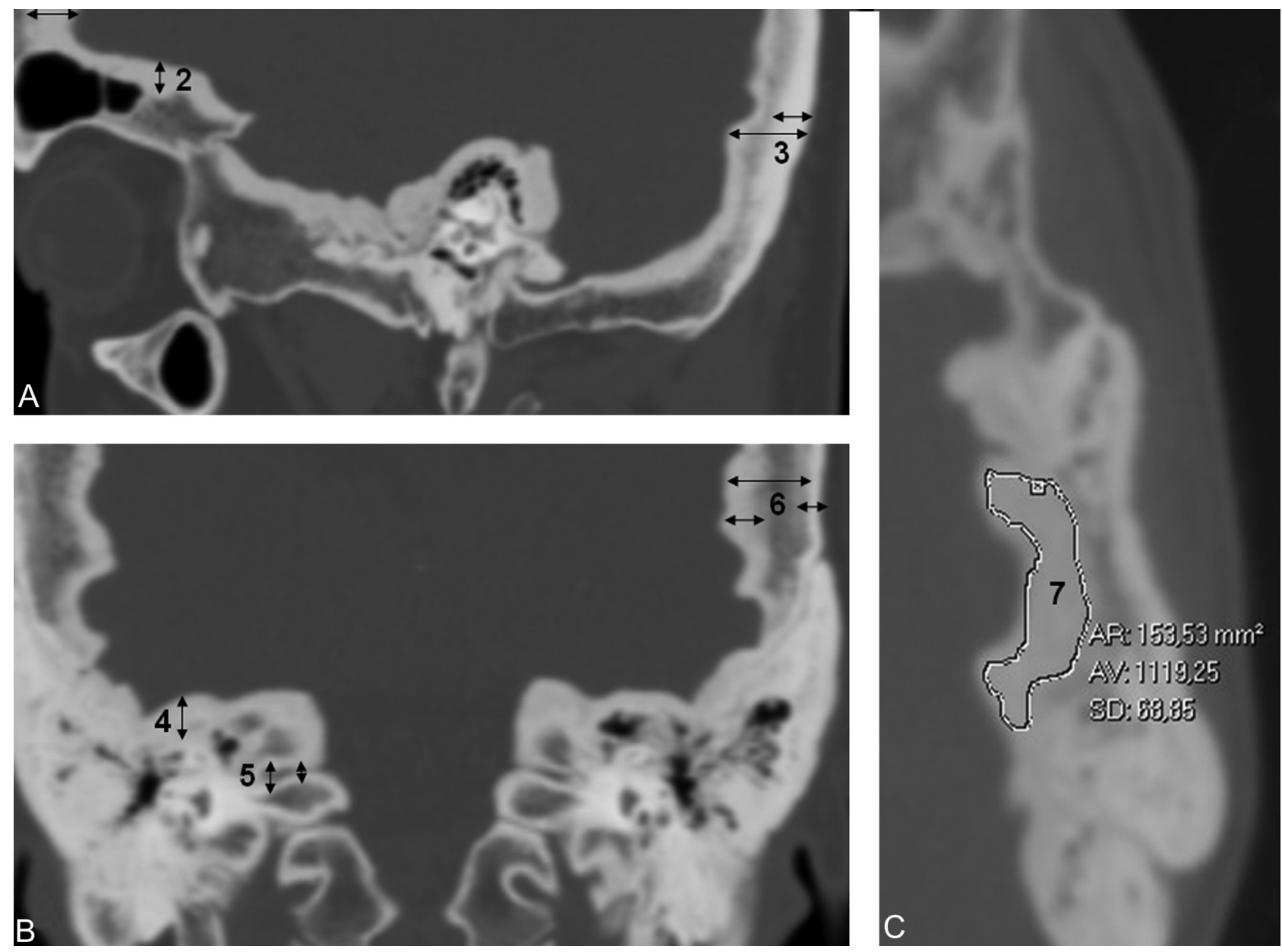

Fig 3. Simplified examples of different measurements. $A$ and $B$, linear measurements of skull thickness and neuroforamen width. $C$, attenuation measurement of freehand region of interest at the inner table of parietal bone. 1, frontal bone measurements; 2 , frontal skull base inner table thickness; 3 , occipital bone measurements; 4 , middle skull base inner table thickness; 5 , internal auditory canal measurements (fundus $=$ lateral part, porus $=$ medial part); 6 , parietal bone measurements, and 7 , parietal inner table attenuation measurement.

\begin{tabular}{|c|c|c|c|c|c|c|c|c|c|c|c|c|c|}
\hline & \multicolumn{3}{|c|}{$\begin{array}{c}\text { Group } 1 \\
\text { Fam }+\mathrm{HCl}+ \\
\end{array}$} & \multicolumn{3}{|c|}{$\begin{array}{c}\text { Group } 3 \\
\text { Matches Group } 1\end{array}$} & \multicolumn{4}{|c|}{$\begin{array}{c}\text { Group } 2 \\
\text { Fam }+\mathrm{HCl}-\end{array}$} & \multicolumn{3}{|c|}{$\begin{array}{c}\text { Group } 4 \\
\text { Matches Group } 2\end{array}$} \\
\hline & Sex & Age & Pedigree & & Sex & Age & & Sex & Age & Pedigree & & Sex & Age \\
\hline 1 & $M$ & 9 & IV.2 & 1 & $\mathrm{~F}$ & 7 & 1 & $\mathrm{~F}$ & 3 & IV. $1^{\#}$ & 1 & $\mathrm{~F}$ & 3 \\
\hline 2 & $\mathrm{~F}$ & 10 & IV.14 & 2 & M & 9 & 2 & $M$ & 4 & IV. $15^{*}$ & 2 & $\mathrm{M}$ & 5 \\
\hline 3 & $\mathrm{~F}$ & 13 & IV.12 & 3 & $\mathrm{~F}$ & 11 & 3 & $\mathrm{~F}$ & 4 & IV. $6^{\#}$ & 3 & $\mathrm{M}$ & 5 \\
\hline 4 & $\mathrm{~F}$ & 22 & IV.11 & 4 & $\mathrm{~F}$ & 20 & 4 & $\mathrm{M}$ & 5 & IV. $5^{\#}$ & 4 & $\mathrm{~F}$ & 6 \\
\hline 5 & $\mathrm{~F}$ & 36 & III.3 & 5 & $M$ & 31 & 5 & $\mathrm{M}$ & 7 & IV. $4^{\#}$ & 5 & $\mathrm{M}$ & 9 \\
\hline 6 & $M$ & 39 & III.8 & 6 & M & 39 & 6 & $\mathrm{M}$ & 14 & IV.13\# & 6 & $\mathrm{M}$ & 12 \\
\hline 7 & $\mathrm{~F}$ & 42 & III.2 & 7 & $\mathrm{~F}$ & 39 & 7 & $\mathrm{~F}$ & 22 & IV.10 & 7 & $\mathrm{~F}$ & 20 \\
\hline 8 & $\mathrm{~F}$ & 44 & 111.7 & 8 & $\mathrm{~F}$ & 42 & 8 & $\mathrm{~F}$ & 23 & IV.9 & 8 & $\mathrm{~F}$ & 24 \\
\hline 9 & $F$ & 45 & III.6 & 9 & $\mathrm{~F}$ & 43 & 9 & $\mathrm{M}$ & 25 & IV.8 & 9 & $\mathrm{M}$ & 28 \\
\hline \multirow[t]{3}{*}{10} & $M$ & 68 & ॥. 2 & 10 & $M$ & 67 & 10 & $M$ & 38 & III.2 & 10 & $\mathrm{M}$ & 30 \\
\hline & & & & & & & 11 & $\mathrm{M}$ & 40 & III.5 & 11 & $\mathrm{M}$ & 45 \\
\hline & & & & & & & 12 & $\mathrm{M}$ & 42 & III.4 & \multirow{2}{*}{\multicolumn{2}{|c|}{ Mean age }} & \\
\hline \multicolumn{2}{|c|}{ Mean age } & 33 & & \multicolumn{2}{|c|}{ Mean age } & 31 & \multicolumn{2}{|c|}{$\begin{array}{c}\text { Mean age } \\
\text { (without IV.15) }\end{array}$} & 20 & & & & 17 \\
\hline
\end{tabular}

Note:-M indicates male; F, female; age, age of scan; ${ }^{*}$, excluded, diagnosis uncertain; ${ }^{*}$, unaffected according to genetic linkage analysis (unpublished data); Fam, family member.

All data were analyzed with SPSS version 16 (SPSS, Chicago, Illinois).

\section{Results}

Ten family members displayed abnormalities on their CT scan (group 1, mean age 32.8, range 9-68), while 12 family mem- bers did not (group 2, range 3-42). Of these 12 family members in group 2, 6 were children under the age of 18 years, which is the age an individual is considered to be unaffected, in cases in which radiologic abnormalities are absent (Table 1). Based on genetic linkage analysis (unpublished data), 5 can be considered as unaffected. No genetic analysis was available for 


\begin{tabular}{|c|c|c|c|c|c|c|c|c|c|}
\hline \multirow[b]{2}{*}{ Location } & \multirow{2}{*}{$\begin{array}{c}\text { Normal } \\
\text { Distribution } \\
(+/-)\end{array}$} & \multicolumn{2}{|c|}{$\begin{array}{c}\text { Group } 1 \\
\text { Fam }+\mathrm{HCl}+\end{array}$} & \multicolumn{2}{|c|}{$\begin{array}{c}\text { Group } 3 \\
\text { Controls Matched } \\
\text { with Group } 1 \\
\end{array}$} & \multicolumn{2}{|c|}{$\begin{array}{c}\text { Group } 2 \\
\text { Fam }+\mathrm{HCl}-\end{array}$} & \multicolumn{2}{|c|}{$\begin{array}{c}\text { Group } 4 \\
\text { Controls Matched } \\
\text { with Group } 2\end{array}$} \\
\hline & & Mean $(\mathrm{mm})$ & SD & Mean (mm) & SD & Mean $(\mathrm{mm})$ & SD & Mean (mm) & SD \\
\hline Frontal total & + & $11.2^{\mathrm{b}}$ & 3.2 & $5.9^{b}$ & 1.4 & 5.6 & 1.4 & 5.5 & 1.8 \\
\hline Frontal inner table & - & $3.2^{b}$ & 1.8 & $1.2^{\mathrm{b}}$ & 0.7 & $1.5^{\mathrm{c}}$ & 0.4 & $1.1^{\mathrm{c}}$ & 0.4 \\
\hline Frontal outer table & + & $2.0^{\mathrm{b}}$ & 0.5 & $1.1^{\mathrm{b}}$ & 0.3 & $1.6^{\mathrm{d}}$ & 0.4 & $1.1^{\mathrm{d}}$ & 0.5 \\
\hline Parietal total & - & $9.4^{\mathrm{b}}$ & 3.7 & $2.2^{\mathrm{b}}$ & 1.1 & 2.8 & 0.7 & 2.4 & 1.1 \\
\hline Parietal inner table & + & 1.7 & 1.0 & 1.1 & 0.4 & 1.5 & 0.4 & 0.8 & 0.4 \\
\hline Parietal outer table & + & $1.9^{\mathrm{a}}$ & 0.6 & $1.0^{\mathrm{a}}$ & 0.4 & 1.4 & 0.5 & 1.2 & 0.7 \\
\hline Occipital total & + & $7.6^{\mathrm{b}}$ & 2.1 & $4.9^{\mathrm{b}}$ & 1.5 & 5.6 & 1.2 & 5.0 & 2.0 \\
\hline Occipital inner table & + & $1.9^{\mathrm{a}}$ & 0.9 & $0.9^{\mathrm{a}}$ & 0.2 & $1.2^{\mathrm{c}}$ & 0.3 & $0.9^{\mathrm{c}}$ & 0.3 \\
\hline Occipital outer table & + & 2.4 & 0.8 & 2.0 & 0.5 & 1.7 & 0.5 & 1.6 & 0.6 \\
\hline Frontal skull base & - & $2.9^{b}$ & 2.0 & $0.8^{\mathrm{b}}$ & 0.1 & $1.6^{\mathrm{d}}$ & 0.6 & $0.8^{d}$ & 0.2 \\
\hline Middle skull base & - & $4.3^{b}$ & 1.9 & $0.7^{\mathrm{b}}$ & 0.1 & $1.3^{\mathrm{d}}$ & 0.4 & $0.6^{\mathrm{d}}$ & 0.1 \\
\hline Foramen magnum & + & $1.9^{b}$ & 0.3 & $1.3^{\mathrm{b}}$ & 0.4 & $1.8^{\mathrm{d}}$ & 0.4 & $1.2^{\mathrm{d}}$ & 0.2 \\
\hline Clivus inner table & + & 1.1 & 0.4 & 0.8 & 0.2 & $1.2^{\mathrm{d}}$ & 0.3 & $0.8^{d}$ & 0.3 \\
\hline Porus IAC & - & $1.1^{\mathrm{b}}$ & 0.4 & $4.1^{\mathrm{b}}$ & 0.6 & 4.0 & 0.7 & 4.3 & 0.8 \\
\hline Fundus IAC & + & $2.8^{\mathrm{b}}$ & 1.1 & $5.3^{\mathrm{b}}$ & 1.0 & 5.1 & 0.5 & 5.1 & 0.7 \\
\hline Optic canal & + & 3.7 & 1.6 & 4.2 & 0.8 & 4.1 & 0.5 & 4.0 & 0.8 \\
\hline Vidian canal & + & 1.0 & 0.5 & 0.9 & 0.3 & 1.2 & 0.4 & 1.0 & 0.3 \\
\hline Coronoid suture & + & $4.6^{\mathrm{a}}$ & 1.2 & $3.0^{\mathrm{a}}$ & 0.9 & 2.7 & 1.7 & 4.0 & 1.5 \\
\hline Lambdoid suture & + & $7.0^{\mathrm{b}}$ & 2.4 & $4.0^{\mathrm{b}}$ & 1.4 & 3.9 & 1.5 & 4.5 & 1.6 \\
\hline
\end{tabular}

Note:-Fam indicates family member.

a Paired $t$ test $1-3, P \leq 0.05$.

${ }^{b}$ Paired $t$ test $2-4, P \leq 0.05$

${ }^{c}$ Paired $t$ test $2-4, P \leq 0.005$.

d Paired $t$ test $2-4, P \leq 0.005$.

individual IV.15; hence, this individual was excluded. The mean age of group 2 was 20.3 years. The control group that matches the affected family members is group 3 (mean age 30.8 , range 7-67). The group that matches the unaffected family members is group 4 (mean age 17.0, range $3-45$ ).

\section{Linear Measurements}

Mean measurements of each location are listed by group in Table 2. Mean values were found to be significantly higher in HCI patients compared with their control group for the following outcome parameters: frontal total, frontal inner table, frontal outer table, parietal total, parietal outer table, occipital total, occipital inner table, frontal skull base, middle skull base, foramen magnum, coronoid suture, and lambdoid suture. Significantly lower mean values were found in the porus of IAC and fundus of IAC. For 7 outcome parameters, group 2 had significantly higher mean values than group 4 : frontal inner table, frontal outer table, occipital inner table, frontal skull base, middle skull base, foramen magnum, and clivus.

All total skull thickness measurements (frontal, parietal, and occipital mean values) were found to be larger for males in groups 2, 3, and 4. In group 1, the female group had higher mean values; however, these differences were not statistically significant. Inner table:total thickness ratios to rule out sex influence did not show any different results for the 3 locations. Removal of the minor individuals did not change any results.

To compare the disease progression throughout life at various anatomic locations, scatterplots with outcome values versus age were used to compare groups 1 and 3 (Fig 4). There was frontal, parietal, and occipital skull thickening throughout life in the affected group. Whereas inner table thickening was mainly responsible for this in the frontal bone, in the parietal bone, there was mainly thickening of the diploe (the inner and outer table were stable throughout life, Fig $4 B$ ). In the occipital bone, there was thickening of all 3 layers. The middle and frontal skull base show progressive hyperostosis compared with the clivus and foramen magnum (Fig $4 D$ ). Narrowing of the porus region of the internal auditory canal is one of the first pathologic changes to occur. No decline in group 1 porus width was visualized, because the youngest subjects already had a markedly narrowed porus (less than $1.5 \mathrm{~mm}$ ). Fundus narrowing continued until later in life and was observed to a lesser extent in the control population as well.

\section{Density Measurements}

The assumption of normality could be made for all attenuation measurements so that the paired sample $t$ test could be applied. For general measurements (frontal, parietal, occipital, and petrous bone, and greater wing of the sphenoid bone), there were no significant differences between groups 1 and 3 or between groups 2 and 4 . Groups 2, 3, and 4 displayed a trend of gradually decreasing attenuation values throughout life, as expected in normal bone tissue. ${ }^{5}$

Significantly lower densities were found in group 1 in all inner table areas: greater sphenoid wing, the frontal bone, the parietal bone, and the occipital bone compared with group 3 (Table 3). No differences were found in any trabecular/medullar bone areas. No statistical differences were found in outer table areas, though affected individuals tended to have denser outer table bone than unaffected individuals. Inner table attenuation measurements were lower in affected individuals than outer table attenuation, in contrast to unaffected individuals (Fig 5). Skull sutures in affected individuals generally have a lower attenuation than control subjects. 

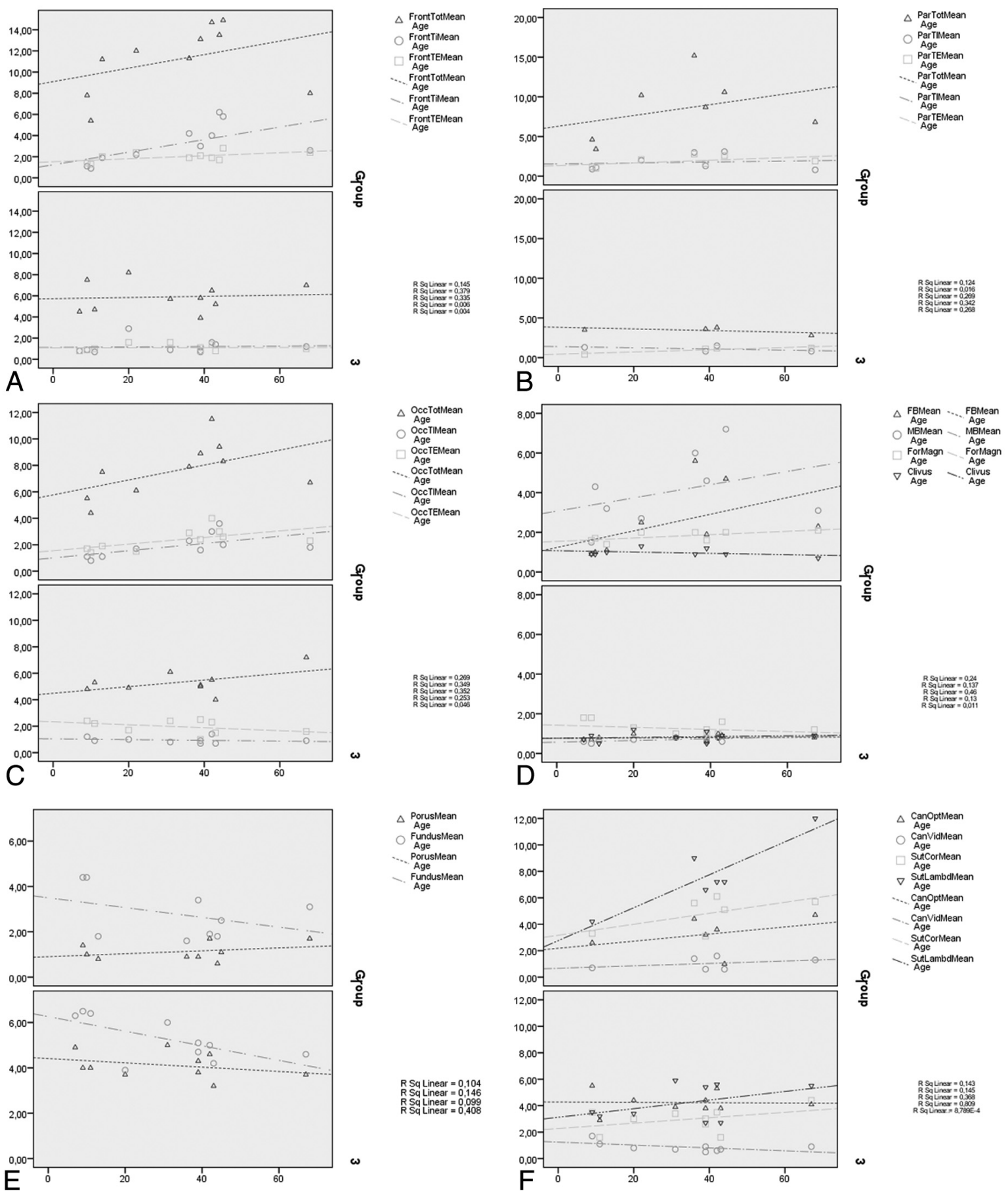

Fig 4. Evolution of groups 1 and 3 per anatomic region. $A$, frontal bone; $B$, parietal bone; $C$, occipital bone; $D$, skull base; $E$, internal auditory canal, and $F$, miscellaneous. $X$-axis $=$ age; $\mathrm{Y}$-axis $=$ distance $(\mathrm{mm}) . \mathrm{TI}=$ inner table (tabula interna); $\mathrm{TE}=$ outer table (tabula externa).

\section{Descriptive Analysis per Affected Region}

Frontal Bone, Frontal Sinus, and Anterior Skull Base. Late in the first decade, radiologic abnormalities become visible in the frontal bone. The first changes are small hypoattenuated islands in the medulla, both medial as well as lateral toward the temporal line (Fig 6). These expand toward the outer table in a balloon-like manner, accompanied with a general thickening of the diploe. Then focal hyperattenuated sclerotic spots arise at the border of inner table and the inner diploe, initially without significant thickening of the inner table. In puberty, the hyperattenuated spots merge and circu- larly augment from the inner table outward, resembling tree rings. The inner border of the significantly thickened diploe stays hypoattenuated at the border with the enlarging inner table. The sclerotic circular layers of hyperattenuated bone augment gradually and fuse in the second or third decade. The inner surface becomes more rugose, and from the fourth decade on, there is generally no more significant growth.

Pneumatization of the frontal sinus occurs earlier and is more extensive than average. The inner table of the frontal sinus, as well as the internal frontal beak (inner aspect of the glabella/nasofrontal area) display hyperostotic changes late in 


\begin{tabular}{|c|c|c|c|c|}
\hline $\begin{array}{l}\text { Location, Affected Group 1; } \\
\text { Reference Location, Matched Group } 3\end{array}$ & $\begin{array}{l}\text { Mean Density Group 1- } \\
\text { Mean Density Group } 3 \text { (HU) }\end{array}$ & Mean 1-3 (HU) & SD & Paired $t$ test $(P)$ \\
\hline Sphenoid inner table 1 & 1022.6 & -359.5 & 231.8 & 0.001 \\
\hline Sphenoid inner table 3 & 1382.1 & & & \\
\hline Sphenoid diploe 1 & 115.5 & -23.1 & 92.0 & 0.448 \\
\hline Sphenoid diploe 3 & 138.6 & & & \\
\hline Frontal inner table 1 & 1191.9 & -158.8 & 60.2 & 0.000 \\
\hline Frontal inner table 3 & 1350.6 & & & \\
\hline Frontal diploe 1 & 427.8 & 102.1 & 176.8 & 0.101 \\
\hline Frontal diploe 3 & 325.7 & & & \\
\hline Frontal outer table 1 & 1489.4 & 141.8 & 199.4 & 0.084 \\
\hline Frontal outer table 3 & 1347.6 & & & \\
\hline Parietal inner table 1 & 1115.0 & -235.6 & 196.1 & 0.011 \\
\hline Frontal inner table $3^{*}$ & 1350.6 & & & \\
\hline Parietal diploe $1^{*}$ & 397.2 & 63.2 & 250.0 & 0.470 \\
\hline Frontal diploe 3 & 334.0 & & & \\
\hline Parietal outer table 1 & 1442.5 & 94.9 & 149.0 & 0.115 \\
\hline Frontal outer table 3 & 1347.6 & & & \\
\hline Occipital inner table $1^{*}$ & 1136.8 & -216.6 & 82.0 & 0.000 \\
\hline Frontal inner table 3 & 1353.4 & & & \\
\hline Clivus 1 & 235.6 & 31.0 & 110.2 & 0.397 \\
\hline Clivus 3 & 204.6 & & & \\
\hline Sphenopetrosal suture 1 & 1176.2 & -30.5 & 186.6 & 0.618 \\
\hline Sphenopetrosal suture 3 & 1206.7 & & & \\
\hline Tympanosquamosal sut. 1 & 1393.8 & -90.5 & 86.9 & 0.009 \\
\hline Tympanosquamosal sut. 3 & 1484.3 & & & \\
\hline Medulla lateral orbita 1 & 271.1 & 5.8 & 128.3 & 0.889 \\
\hline Medulla lateral orbita 3 & 265.3 & & & \\
\hline Exostoses mandible 1 & 1340.0 & $\mathrm{~N} / \mathrm{A}$ & 86.0 & $\mathrm{~N} / \mathrm{A}$ \\
\hline
\end{tabular}

Comparison of bone density of specific location between groups 1 and 3 . Areas indicated with ${ }^{*}$ in group 3 were too small to be measured separately. Therefore, the frontal area was used as reference.

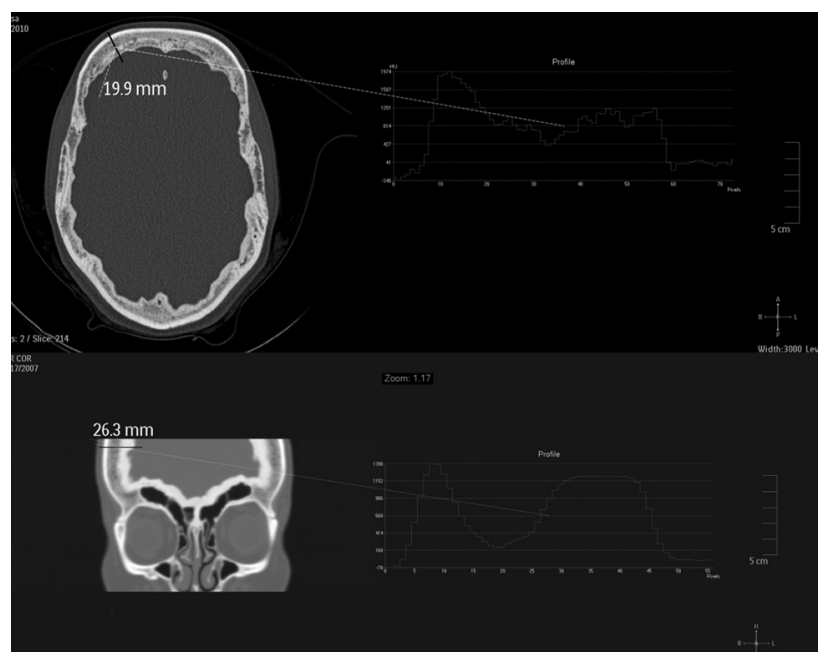

Fig 5. Density profiles of skull transsections in frontal (upper) and frontotemporal (lower) bone (upper) region. $\mathrm{X}$-axis $=$ distance; $\mathrm{Y}$-axis $=$ attenuation $(\mathrm{HU})$. The higher peak correlates with the outer table. Inner table attenuation measurements are found to be lower in affected individuals than outer table attenuation, in contrast to unaffected individuals.

the second decade. There is limited thickening of the outer table at the level of the sinus and the frontal bone as well.

Parietal and temporal bones. Abnormalities in the parietal bone start off as early as in the frontal bone. Hypoattenuated areas arise at the endosteal side of the diploe from the age of 8 years. Initially, only the diploe grows thicker and the inner surface becomes irregular, without obvious thickening of the inner table. The petrosquamous suture lines become sclerotic;

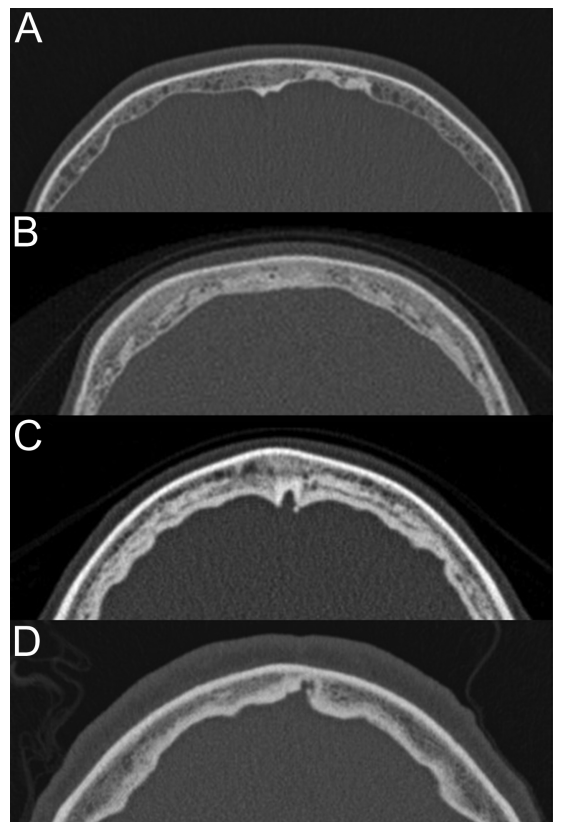

Fig 6. Development of abnormalities in the frontal bone, axial images. $A$, age $9 ; B$, age 16 ; $C$, age $23 ; D$, age 68

in this area, the 3 bone layers (inner table, outer table, and diploe) cannot be differentiated. In the second and third decades, there is further thickening of the diploe, and hyperostosis of the inner table becomes apparent. The same pattern is observed as in the frontal bone: a hypoattenuated demarcation between inner table and diploe. In contrast to the frontal bone, 


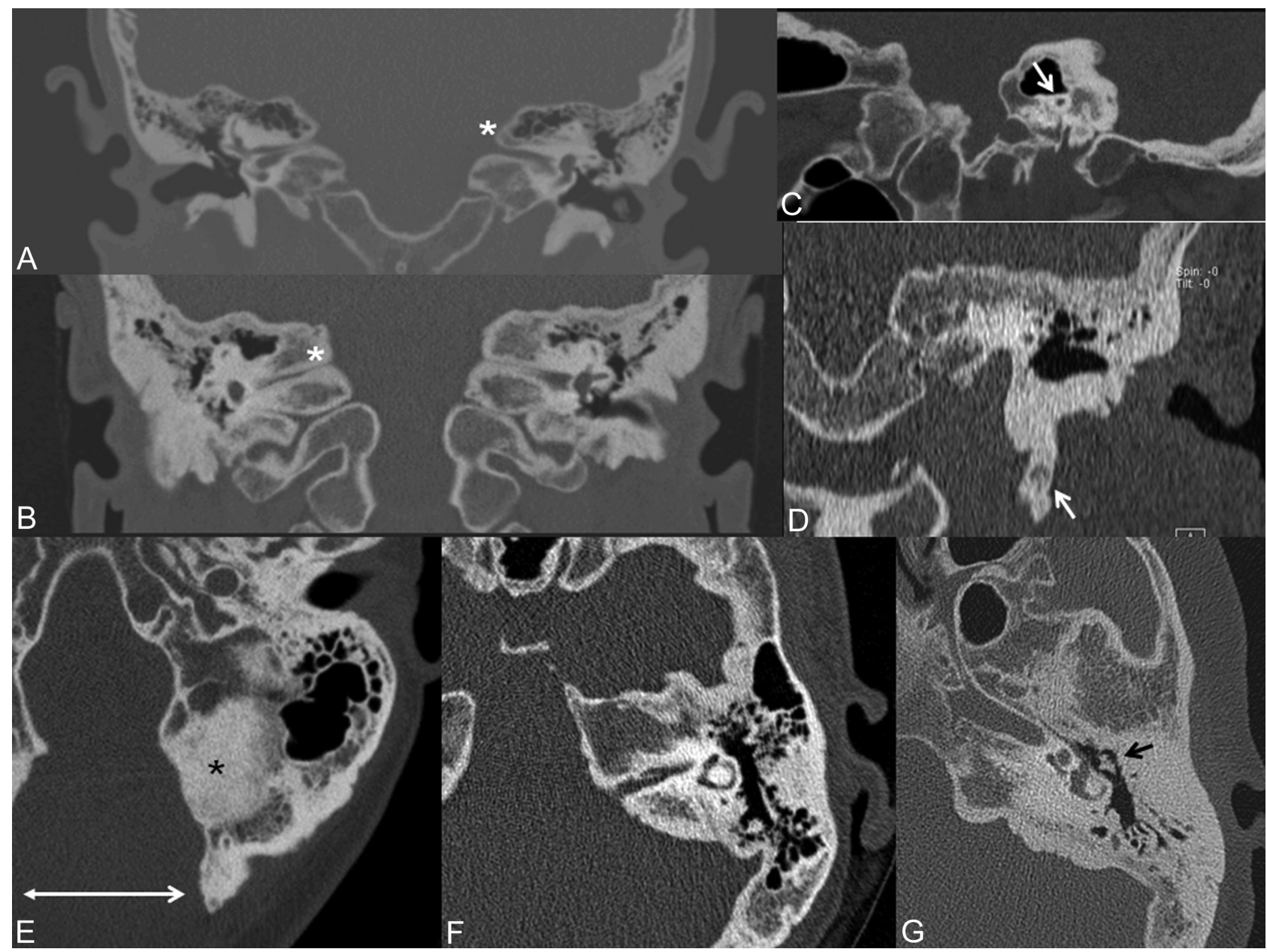

Fig 7. Temporal bone. A, 9-year-old boy: Hyperostotic superior (asterisk) and inferior lip of the IAC (coronal reconstruction). B, 41-year-old woman: Pinpoint internal auditory canal (arrow, sagittal reconstruction). $C$, Progressive bilateral narrowing of the IAC in a 16-year-old girl (asterisk, coronal reconstruction). D, Hyperostotic stylomastoid process in a 44-year-old woman (arrow, coronal reconstruction). E-G: Axial images of left temporal bones with extensive hyperostosis in posterior fossa (asterisk) after foramen magnum decompression (double-headed arrow). E, 41-year-old woman with extensive pneumatization progressively substituted by sclerotic bone ( $F$ and $G$ ). Note the middle ear space is not affected (arrow G).

the hyperostotic layer does not have a circularly layered aspect. From this age, disease progression is variable per individual.

The temporal bone (Fig 7) is generally extensively pneumatized, also toward the petrous apex and the zygomatic root. The first temporal bone abnormalities are visible by the age of 10 years. The lateral mastoid, just cranial to the external ear canal, has a sclerotic aspect in all individuals, seemingly a sclerotic petrosquamous suture. In the second decade, the sclerosis of the petrosquamous suture (or Körner septum in the mastoid) expands, causing obliteration of the lateral mastoid and air cells around the zygomatic root.

Endosteal thickening of the temporal bone starts at the posterior aspect and the internal auditory canal region in the late first or early second decade, first as small hyperattenuated speckles. A clear endosteal hyperostotic margin becomes visible later in the second decade, now also including the anterior and superior aspect of the petrous bone.

Internal auditory canal narrowing is invariably visible at the level of the porus in the late first decade. The petrous apex, even when initially pneumatized, becomes sclerotic. There is thickening of both the inferior and superior lip of the canal; however, bone accretion of the superior lip seems to contrib- ute most of the narrowing. The canal size decreases until there is a pinpoint lumen $(0.5-1 \mathrm{~mm}){ }^{6}$

The sclerotic stylomastoid process becomes hyperostotic and sclerotic in older individuals as well.

Sphenoid and Ethmoid Bones. The endocranial side of the greater sphenoid wing displays the same abnormalities as the frontal bone: hypoattenuated areas of the diploe and sclerotic endosteal foci appearing late in the first decade. Fusion sites with other adjacent osseous structures have a sclerotic aspect as well: the sphenosquamous suture (connection with temporal bone), sphenofrontal suture, and sphenozygomatic sutures. Fusion with the clivus is not yet established at this age. The cribiroform plate and the ethmoid cells are, as yet, unaffected. The anterior midline aspect of the sphenoid bone, the jugum, or corpus sphenoidale facing the ethmoid sinuses becomes sclerotic even before the sphenoid sinus is fully pneumatized. When the sphenoid sinus is developed, the anterolateral wall of the sinus becomes more explicitly thickened than in unaffected individuals. In the second decade, this hyperostosis becomes more evident and the (anterior portion of the) lamina papyracea becomes involved as well. The clivus fuses with the sphenoid bone without any evident sclerosis at this 


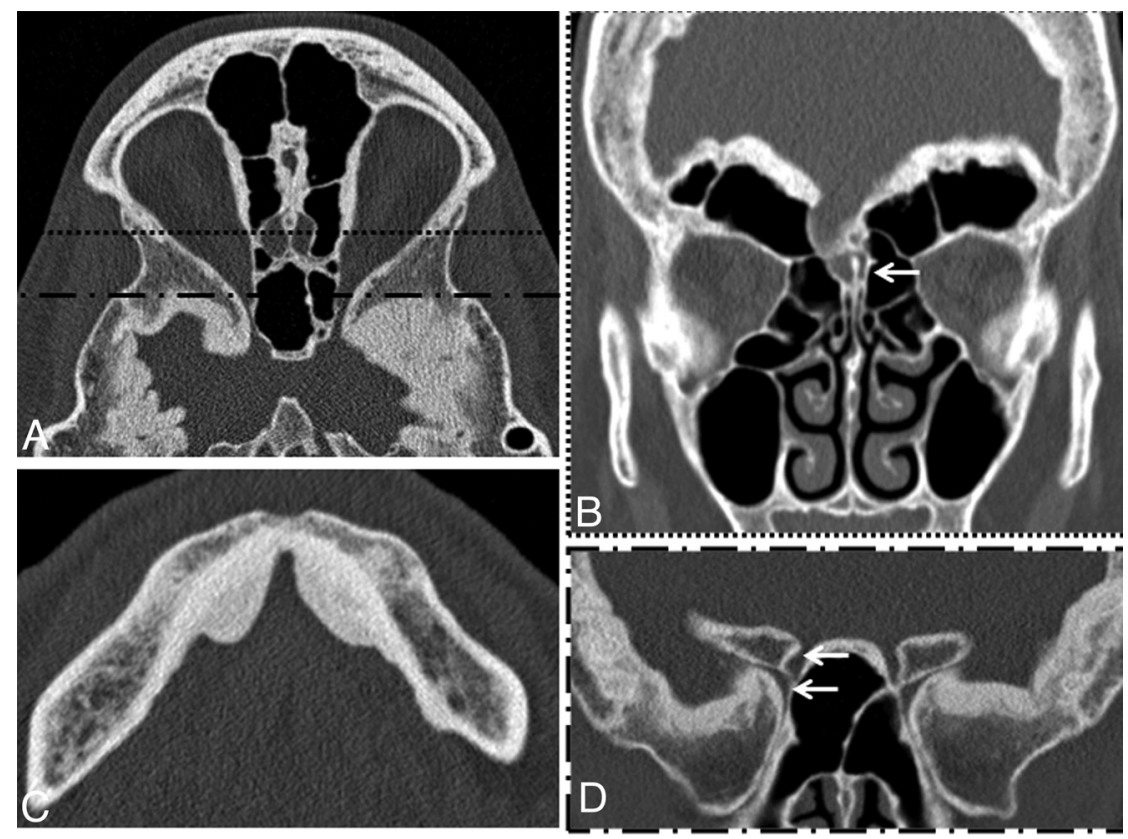

Fig 8. Sphenoid, ethmoid, mandible. A, Axial image of 23-year-old woman: hyperostosis of endosteal greater sphenoid wing, decreased space in temporal lobe area; hyperostotic lamina papyracea and cribriform plate area. Anterior line corresponds with coronal image $B$ (different patient); posterior line corresponds with the coronal image $D$ (same patient). $B$, Coronal image of 41-year-old woman showing extensive supraorbital pneumatization and inclusion of unaffected crista galli (arrow). $C$, Axial image of mandibular exostoses in a 68-year-old patient. Note that the inner table of the mandible shows a normal aspect. $D$, Coronal image (same patient as $A$ ) of the greater and lesser sphenoid wings. Note narrowing of the optic canal (upper arrow) and the superior orbital fissure (lower arrow).

fusion site. Until the mid-20s, there is significant progression of disease at the endocranial side of the greater and lesser sphenoid wings (Fig 8A). The sclerotic endosteal borders transform into a well-defined hyperattenuated hyperostotic bone layer, which becomes continuous with the parietal and petrous bones. Remarkably, the endocranial side of the corpus of the sphenoid and the tuberculum sellae are spared.

If an individual is severely affected, the patency of the superior orbital fissure is potentially compromised due to hyperostosis of both the superior aspect of the greater sphenoid and the inferior aspect of the lesser sphenoid wing. The patency of the optic canal is specifically at risk at the narrowest part, where hyperostosis of the superolateral aspect of the sphenoid sinus and hyperostosis of the medial side of the lesser sphenoid wing occur (Fig 8D).

Middle and Posterior Skull Base. Symptomatology of neural and vascular structures passing the various middle skull base neuroforamina is dependent on the degree of encroachment. The round and oval foramina can be narrowed in their proximal part, leading to dysfunction of the second and third branches of the trigeminal nerve in severely affected individuals. The Vidian nerve and pterygopalatine fossa are never narrowed. The carotid canal is not affected at all, whereas asymptomatic sigmoid sinus narrowing is present in individuals with extensive posterior fossa hyperostosis. The jugular foramen is not narrowed. The foramen spinosum and hypoglossal canal are patent in all patients. In some individuals we found an acquired Chiari Malformation. The reason is probably downward pressure of the cerebrum and cerebellum due to hyperostosis. Hyperostosis in the posterior fossa area is usually less extensive than in other parts of the skull.

Skull Sutures. Skull sutures are affected to a various extent from late childhood. There is explicitly no endosteal hyperos- tosis at the fusion sites, however osteosclerosis occurs parallel to the suture in the direction of the connecting plates.

Mandible. Changes occur to the mandible later in life (Fig $8 C$ ). There is smooth delineated ellipsoid deposition of bone at the inner (oral) side of the anterior half of the mandible, sparing the midline. The attenuation is lower that cortical bone, similar to the cranial abnormalities. This is only observed from the age of 36 years onward. Unlike abnormalities of the frontal region and the skull base region, the otherwise intact inner cortex can still be differentiated from the diseaserelated bone deposition.

\section{Discussion}

In HCI, endosteal hyperostosis occurs in the parietal, frontal, occipital, sphenoid, ethmoid, and temporal bones without obliteration of the diploe. The most marked change is thickening of the inner table of the calvaria, except for the parietal region, where broadening of the diploe is more explicit. The reason for this difference is unclear. The appearance of the outer table of the patient group is not disturbed but can be slightly thickened in the adult affected individuals. The cranial nerve deficits are caused by hyperostosis of the skull base, resulting in narrowing of the neuroforamina. Furthermore, skull sutures become more sclerotic than in unaffected individuals, and the lateral parts of the mastoids and the petrous apices undergo sclerotic changes. The stylomastoid process is affected, showing broadening and exostoses. All patients develop mandibular exostoses at the interior surface of the anterior half of the mandible at a later age. Clinically and upon descriptive radiologic examination, female patients are more severely affected than males. There is no statistical support for this phenomenon. The diploe never obliterates because the bone accretion seems to take place at the endosteal side of a 
hypoattenuated circular "front," with ballooning spongeous spots in the diploe, and net bone growth follows an inward (endosteal) direction. In similar sclerosing bone dysplasias, such as Camurati-Engelmann disease, Van Buchem disease, and sclerosteosis, there is obliteration of the diploe. However, whether this bone accretion actually takes place at the outside of the inner table or at the inside of the diploe can only be proved histologically.

The outcome of the analyses of the internal auditory canal confirm the management as has earlier been proposed by our group. Narrowing of the porus occurs, at a very young age, to a size that causes dysfunction of the facial and vestibulocochlear nerves in almost all patients. Early intervention (decompression) is advised. ${ }^{6}$ The fundus gradually narrows at a later age (down to $2 \mathrm{~mm}$ ), just as it does in the normal population $(4 \mathrm{~mm})$.

For the optic system, it is harder to arrive at a straightforward conclusion. Although there is no statistically significant difference between the widths of the optic canal in the affected individuals, the difference is apparent with a greater individual variation, as seen in the larger standard deviation. Impairment of the optic nerve, if any, occurs at the narrowest point of the optic canal, due to hyperostosis of the medial lesser sphenoid wing, as depicted in Fig $8 A$ and $D$. Another plausible option could be impairment of venous outflow of the ophthalmic vein due to a narrowed superior orbital fissure (due to hyperostosis of the medial greater sphenoid wing; Fig $8 D$ ).

Paranasal sinus and petrous bone pneumatization is remarkably extensive in all young patients; however, this could be a non-disease-specific coincidental finding (Fig $8 B$ ). The young affected individuals have a fully developed frontal sinus at the age of 7 years, whereas the sinus does not normally appear before this age. The early extensive petrous bone pneumatization is generally replaced by secondary sclerosis.

In the available literature, little is found about reference values of bone attenuation in the skull. In the field of oral implants, studies have been performed to optimize implant osseointegration by correlating the attenuation to the bone strength. Misch et $\mathrm{al}^{7}$ have proposed the following classification: attenuated cortical (D1, >1250 HU), porous cortical (D2, 850-1250 HU), coarse trabecular (D3, 350-850 HU), and fine trabecular bone (D4, <400 HU). The hyperostotic bone in HCI has the appearance and also the densitometric characteristics of porous cortical bone (D2), resembling the attenuation of abnormalities in Paget disease and fibrous dysplasia.

The outer table of the patients' calvaria have similar attenuation values as the unaffected population and the control patients. The trabecular bone (diploe) at different sites of patients is similar to mandibular trabecular bone, as described in oral implant literature $(240-380 \mathrm{HU}) .^{8}$ The attenuation degradation can be compared with the process that is visible in otosclerosis, where attenuated (D1) cortical bone of the otic pit is transformed into porous cortical bone containing more fibrous and less calcified tissue., ${ }^{9,10}$

There is not yet a definite explanation why some particular areas are involved and others not. Given the fact that only the craniofacial area is involved, there must be a local factor that causes bone metabolic disturbance. The inward (endosteal) hyperostosis suggests a potential role of the dura mater, which is known to produce signaling substances involved in bone metabolic pathways. ${ }^{11}$ However, not all structures adjacent to dura are affected equally: the occipital area is less affected than the temporal area, there is hardly any hyperostosis in the area of the clivus and foramen magnum, and the spine is not affected at all. In addition, the stylomastoid process and the mandible display abnormalities even though these are not adjacent to dura. The course of the disease could also give a clue about the pathogenesis. Abnormalities are not seen before the late first decade. If regional (dural) factors do induce abnormal growth, different gene expression in juvenile and adult dura possibly explain why abnormal growth does not occur in all stages of life. ${ }^{12}$ Different cellular pathways are described that control the growth pace of the skull and the appropriate timing of skull suture closure. ${ }^{13}$ Defects in one of these mechanisms occur in disorders in the group of craniosynsostoses (eg, Crouzon and Apert syndromes) as well. ${ }^{4}$

Although the genetic transmission pattern is clearly autosomal dominant, and "unaffected family members" obviously have no abnormal radiologic hallmarks and no symptoms, there are some significant differences in contrast to their control group. This suggests incomplete dominance; however, this can only be proved after the detection of the underlying genetic defect.

\section{Conclusions}

$\mathrm{HCI}$ is the only genetic hyperostotic bone dysplasia limited to the craniofacial area. The hyperostotic bone is less attenuated than normal cortical bone. The observed radiologic abnormalities match the possible impairment of the olfactory, optic, trigeminal, facial, and vestibulocochlear nerves. The pathogenesis remains obscure until the underlying genetic defect is found, but disturbance in local bone metabolic pathways appear to be involved.

\section{References}

1. Manni JJ, Scaf JJ, Huygen PL, et al. Hyperostosis cranialis interna: a new hereditary syndrome with cranial-nerve entrapment. $N$ Engl $\mathrm{J}$ Med 1990;322:450-54

2. Waterval JJ, Stokroos RJ, Bauer NJ, et al. Phenotypic manifestations and management of hyperostosis cranialis interna, a hereditary bone dysplasia affecting the calvaria and the skull base. Am J Med Genet A 2010;152A:547-55

3. Rimoin DL, Cohn D, Krakow D, et al. The skeletal dysplasias: clinical-molecular correlations. Ann N Y Acad Sci 2007;1117:302-09

4. Superti-Furga A, Unger S. Nosology and classification of genetic skeletal disorders: 2006 revision. Am J Med Genet A 2007;143:1-18

5. Skrzat J, Brzegowy P, Walocha J, et al. Age dependent changes of the diploe in the human skull. Folia Morphol 2004;63:67-70

6. Waterval JJ, Stokroos RJ, De Bondt RB, et al. Facial nerve decompression via middle fossa approach for hyperostosis cranialis interna: a feasible therapeutic approach. J Laryngol Otol 2009;123:1177-80

7. Misch CE, Dietsh-Misch F, Hoar J, et al. A bone quality-based implant system: first year of prosthetic loading. J Oral Implantol 1999;25:185-97

8. de Oliveira RC, Leles CR, Normanha LM, et al. Assessments of trabecular bone density at implant sites on CT images. Oral Surg Oral Med Oral Pathol Oral Radiol Endod 2008;105:231-38

9. Kawase S, Naganawa S, Sone M, et al. Relationship between CT densitometry with a slice thickness of $0.5 \mathbf{~ m m}$ and audiometry in otosclerosis. Eur Radiol 2006;16:1367-73

10. Grayeli AB, Yrieix CS, Imauchi Y, et al. Temporal bone density measurements using CT in otosclerosis. Acta Oto-laryngol 2004;124:1136-40

11. Warren SM, Greenwald JA, Nacamuli RP, et al. Regional dura mater differentially regulates osteoblast gene expression. J Craniofac Surg 2003;14:363-70

12. Wan DC, Aalami OO, Wang Z, et al. Differential gene expression between juvenile and adult dura mater: a window into what genes play a role in the regeneration of membranous bone. Plas Reconstruct Surg 2006;118:851-61

13. Opperman LA, Adab K, Gakunga PT. Transforming growth factor-beta 2 and TGF-beta 3 regulate fetal rat cranial suture morphogenesis by regulating rates of cell proliferation and apoptosis. Devel Dyn 2000;219:237-47 